\title{
Las luchas campeñas en dos novelas bananeras hondureñas
}

\author{
The campeño struggle in two honduran banana novels \\ Ivannia Barboza Leitón \\ Universidad de Costa Rica, San José \\ oRCID: https://orcid.org/o000-0003-0057-I98I \\ ivannia.barboza@ucr.ac.cr \\ ISSN-0185-4259; E- ISSN: 2007-9176 \\ DoI: http://dx.doi.org/10.28928/ri/912021/aot1/barbozaleitoni
}

\begin{abstract}
Resumen
Este artículo analiza un corpus de la novela bananera hondureña desde la visión de héroes y antagonistas de las personas trabajadoras en las plantaciones o campeños. Dicho sustento subyace en la hipótesis de que los personajes gravitan en complejas relaciones intersubjetivas; la tensión es sustentada por la companía bananera junto con los gobiernos de turno. Me interesa mostrar que en la convivencia laboral y social de los campeños surgen héroes que procuran, con claro sentido de conciencia, cohesionar el movimiento de los trabajadores frente al poderío de la compañía. Cuando interaccionan con sus semejantes, es posible reconocer en ellos una estructura dialógica que apunta a diversos intereses, lo que conlleva a un espectro de valores. Para esto, el análisis semiótico vehicula semas definidos como lealtad al movimiento de huelga frente a la traición; por lo tanto, se traduce en dialéctica cambiante por las circunstancias y los intereses individuales y colectivos. Las conclusiones sustentan que en el mundo narrado de las novelas hay una conciencia de alteridad que se despliega no solo hacia la aceptación y el rechazo; al contrario, hay nexos entre los protagonistas consigo mismos, con los demás y con la compañía como parte de un sentido identitario nacional y con el mundo.
\end{abstract}

Palabras clave: literatura centroamericana, novela bananera, Honduras, campeños, otredad-alteridad.

\footnotetext{
Abstract

This article analyzes a corpus of the Honduran banana novel from the point of view of heroes and antagonists of working people on plantations or campeños. This support underlies the hypothesis that the characters gravitate in complex intersubjective relationships, the tension is sustained by the banana company together with the governments of the day. I am interested in showing that in the labor and social coexistence of the villagers heroes arise who seek, with a clear sense of conscience, to unite the workers' movement against the power of the company. When they interact with their peers, it is possible to recognize in them a dialogic structure that points to different interests, which leads to a spectrum of values. For this, the semiotic analysis conveys semas defined as loyalty to the strike movement in the face of betrayal, therefore, it translates into changing dialectics due to the circumstances and individual and collective interests. The conclusions support that in the narrated world of the novels, there is an awareness of otherness that unfolds not only towards acceptance and rejection, on the contrary, there are links between the protagonists with themselves, with others and with the company as part of a sense of national identity and with the world.

Keywords: Central American literature, Honduras, banana enclave, identity, otherness.
}

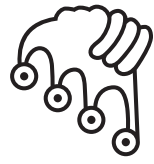

IZTAPALAPA

Agua sobre lajas 
Este imperio era, sin duda, la obra de un hombre solo: Sam Zemurray. Ahora cientos de personas dependían de él.

Para ello había trabajado de sol a sol y de luna a luna, viajando por toda Centroamérica y el Caribe en condiciones heroicas, disputándose el terreno con otros aventureros como él a punta de pistola y a cuchillazos, durmiendo en pleno campo cientos de veces, devorado por los mosquitos y contrayendo fiebres palúdicas que lo martirizaban de tanto en tanto, sobornando a autoridades y engañando a campesinos e indígenas ignorantes, y negociando con dictadores corruptos gracias a los cuales -aprovechando su codicia o estupidez- había ido adquiriendo propiedades que ahora sumaban más hectáreas que un país europeo de buena contextura, creando miles de puestos de trabajo, tendiendo vías férreas, abriendo puertos y conectando la barbarie con la civilización.

(Mario Vargas Llosa, Tiempos recios, pp. 17-18).

-Pues todo aquel movimiento de progreso desapareció como por brujería. Hoy no existen ni los caminos de tierra. El monte se va comiendo las hasta ayer florecientes ciudades y las gentes huyen a otros lugares de la costa o del interior; pocas personas se arriesgan a vivir allá, expuestas a todo. Colón es un departamento cadáver. Lo mató la Compañía y el gobierno «azul». Dicen que Cristo resucitó a Lázaro ya hediondo, pero en esos lugares no hay Cristo. —Pero sí ha habido Judas! —exclamó exaltado Marcos.

(Ramón Amaya Amador, Prisión verde, p. 84). 


\section{Introducción}

$\tau \begin{aligned} & \text { ay dos personajes en la novela Destacamento rojo, de Ramón Amaya Ama- } \\ & \text { dor, que reparten volantes contra el gobierno para dirigir al pueblo a un } \\ & \text { levantamiento. Al cobijo de la oscuridad, del silencio cuando no hay patru- }\end{aligned}$ llas, Eladio Ulloa y Pedro Bravo escuchan a los perros ladrar, luego señalan:"-Esos perros son una denuncia... / -Deben estar al servicio del gobierno... (1962: 289). ${ }^{1}$

Las circunstancias previas al movimiento huelguístico, la huelga misma y los resultados retratados en Prisión verde y en Destacamento rojo representaban el largo transitar de una mayoría obrera que se sentía no solamente exhausta y explotada, sino que veía esfumarse las esperanzas en cuanto al mejoramiento económico que creyó encontrar en el enclave bananero en Honduras. La cita textual anterior evidencia el ambiente tenso reflejado en una gama de conductas humanas como la traición por unas cuantas monedas, el espionaje y la acusación ante las autoridades de gobierno por incitar a la violencia con el llamado a huelga, que se encontraba ad portas con tal de visibilizarse del lado de la compañía bananera ${ }^{2}$ y, por lo tanto, de la administración de turno.

1 No es casual la escena en la que los dos hombres charlan bajo el amparo de la oscuridad, con el temor de ser delatados hasta por los animales. Ese retrato de la sociedad hondureña en la obra Destacamento rojo coincidía en mostrar la tensa relación existente entre las autoridades políticas y los dirigentes de organizaciones obreras y comunistas durante los años en los que los movimientos sociales propugnaban por reivindicaciones laborales. Mario Posas acota al respecto: "Los esfuerzos realizados por las organizaciones sindicales influidas por los comunistas hondureños para crear sus propias federaciones sindicales durante estos años formativos del sindicalismo legalizado, fueron bloqueados por el Estado, que para evitar su desarrollo: I) apoyó alternativas organizativas más moderadas; 2) se negó a otorgarles personería jurídica y 3) persiguió a sus líderes" (2019: 264).

2 El enclave bananero, según Viales (2006), quien lo toma de Torres-Rivas, "marca[r] una diferencia decisiva en la formación de los Estados nacionales enfrentada a la categoría de 'propietarios nacionales"; por lo tanto, desde su perspectiva no es un concepto económico sino más bien político, y su capacidad heurística reside en los efectos internos, políticos, económicos y culturales que tiene una producción nacional en manos nacionales y otra en poder del capital extranjero, sobre todo cuando éste [sic] "enclaviza la producción nacional" (2006:97). El enclave llegó a ser denominado por antonomasia entre los sectores trabajadores centroamericanos como la compañía en referencia a la United Fruit Company, empresa constituida por Minor C. Keith (Estados Unidos, I848-1929) en 1899. También por extensión el empleo de la United Fruit Company se redujo a ufCo, la Frutera, el Pulpo o la Yunai (término empleado en Costa Rica). 
Analizar las relaciones intersubjetivas de los personajes trabajadores del enclave bananero en Prisión verde (1950) y en Destacamento rojo (1962), de Ramón Amaya Amador, como formas de reconocimiento de sí mismos y de los otros, desde el espectro semiótico constitutivo de héroes y antagonistas es el objetivo propuesto. Considero dos hipótesis: la primera parte de que hay una constitución clara de héroes y antagonistas en el corpus que evidencia, al decir de Tatiana Bubnova (1997: 260), una interacción en cuya base descansa el acto ético. Estos sujetos narrativos, desde los ámbitos en los que se encuentran, son conscientes del papel que desempeñan en los movimientos obreros del enclave en Honduras, y de paso asumen también quiénes son los oponentes en los propósitos predefinidos al interior de las novelas.

Como reflejo de lo anterior surge la segunda hipótesis, porque Honduras en la época del enclave bananero experimentó a nivel macropolítico una sucesión de dictaduras. Estas se reconocen en Tiburcio Carías Andino, quien gobernó de 1932 a 1936, periodo que se extendió en forma dictatorial hasta 1949. Resalto que en su mandato impulsó la casi desaparición del Partido Comunista Hondureño. Presidentes como Juan Manuel Gálvez Durón (1949-1954), Julio Lozano Díaz (1954-1956) y Ramón Villeda Morales (1957-1963) representan un continuum de la administración de Carías Andino. Los periodos presidenciales anteriores coadyuvaron en la vivencia frustrada de trabajar sin condiciones justas (jornadas de ocho horas, seguro médico, pago de horas extras, entre otros), requerimientos sociales que se supone el Estado hondureño debía brindar o exigir de las compañías bananeras para sus empleados.

Consecuente con el objetivo propuesto, el aparato teórico-metodológico que sustenta el estudio proviene de la noción ética que, a propósito de Bajtín, desarrolla Bubnova (1997). El primero señala "El individuo no existe fuera de la otredad" (1998: 15I); con ello Bubnova interrelaciona la alteridad consciente manifiesta en un sujeto del "deber ser" [cursivas en el original] (1997:262) por cuanto reconoce sus circunstancias y los eventos que le corresponden. En el corpus del subgénero de la novela bananera predomina un carácter colectivo en cuanto a mostrar, efectivamente, los dos polos generados por la presencia del enclave: la élite estadounidense y el personal empleado del país en el que se establece. Con la alteridad, manifiesta en complejas relaciones laborales, los personajes experimentan una fuerza que atrae o expulsa a los que terminan por manifestarse diferentes tanto en sus actuaciones como en las subjetividades; es un proceso identitario en el que se reconoce la suma del ser individual y el ser de los otros. 
Del mismo modo, en los campeños ${ }^{3}$ son reconocibles actitudes que van desde hechos que los definen como héroes (con respecto a los semejantes subyugados por la compañía estadounidense) y antagonistas (con respecto también a quienes procuran mejorar su horizonte de vida). En la lucha social y moral que se libra en las plantaciones subyace una interpretación de sentido constituida en una resignificación de las complejas relaciones humanas, en las que es posible reconocer "La presencia del otro [que] confiere un sentido y aporta valores a la existencia del yo"; de este modo, "el principio ético no es la fuente de los valores, sino el modo de relacionarse con los valores" (Bocharov, citado en Bubnova, 1997: 266-267).

Por lo anterior, en concordancia con la teoría, utilizo el aporte metodológico desde la semiótica porque redirecciona hacia dos polos los valores mencionados por Bubnova: hay personajes con valores constructivos para la lucha social que actúan con el deber moral de los héroes ante las afrentas de la compañía, y los otros que, semejantes en un principio, deciden oponérseles desde otra concepción en la que los intereses se han tornado individuales y egoístas. Gastón Gaínza (1994) acota al respecto: "puede afirmarse que la dialéctica de la otredad puede representarse como un conjunto entre: 'aceptación-rechazo'. La aceptación supone asumir la otredad e incorporarla en un 'nosotros', ampliando de ese modo el espacio social de la mismidad" (1994: 16).

Para el desarrollo del objetivo propuesto conviene, por efectos de orden y continuidad en la línea de análisis, presentarlo de la siguiente manera: hay cuatro apartados, el primero contextualiza las novelas y su crítica y al autor. El estudio del corpus se divide en dos: "En este barracón no hay 'orejas" y "Para que no sirvan de rompehuelgas"; finalmente aparecen las conclusiones.

\section{Acerca de las obras y el autor}

La revisión del estado de la cuestión arroja estas posibilidades cercanas: destaco los estudios de Longino Becerra (1962, 198I), Hellen Umaña (2003), Carlos Amaya Fúnez (2004), Valeria Grinberg Pla y Werner Mackenbach (2009), Suyapa G. Portillo Villeda (20II), John Soluri (2013), Gerardo Aguilar Molinari (2016) y Héctor Pérez Brignoli (2018). Sobresale la escasa aportación crítica acerca de Destacamento rojo, probablemente debido a que Prisión verde se lee más como novela bananera,

3 "Campeño, ña I. adj. Hond. campesino (| perteneciente al campo). 2. adj. Hond. campesino (| propio de la persona campesina).3. m. y f. Hond. Persona que trabaja en las compañías bananeras" (DRAE, 2O2O). 
mientras que en el caso de Destacamento rojo las razones podrían ser dos: la primera compete a que dicha novela fue censurada por diversas administraciones, como la de Ramón Villeda Morales (1957-I963), según menciona Becerra en el primer Prólogo a la edición publicada en Honduras (198I). La lectura estigmatizada de la obra por asociación con su autor es la segunda, además de que quizás no fuera asociada con Prisión verde y con ello el reconocimiento como narrativa representativa del enclave bananero. Lo que resulta válido también en la configuración bibliográfica acerca de las obras, y en este caso en particular, es que Becerra muestra con datos de personajes e individuos de la vida política de Honduras dos caras de la moneda que la compañía bananera lanzó en las costas bananeras: la traición y la fidelidad de ambos polos en la dinámica comercial. También Amaya Fúnez en el Prólogo a la edición más reciente de Destacamento rojo en el 2004, coincide en denunciar los avatares que han significado las ediciones de la obra para rescatar finalmente la necesidad de que sea leída como parte de la memoria histórica de la nación centroamericana (2019: párr. 3).

Umaña revisa las obras de Amaya Amador desde presupuestos del formalismo ruso; las considera "permeadas por los postulados del realismo socialista y, aunque este hecho generalmente opera como un lastre, ello no disminuye el valor intrínseco de algunas de sus novelas" (2003: 195). Con Prisión verde valora el estilo simple, la juzga "Mesurada en el aspecto ideológico" (2003: 198), mientras que en Destacamento rojo con caracteres planos se libra una lucha de "dos personajes colectivos en oposición antagónica: el imperialismo norteamericano y las fuerzas del socialismo" (2003: 206). Grinberg Pla y Mackenbach consideran las novelas como parte de aquellas obras de la región que incitan "el activismo político-sindical y que además articulan un discurso antiimperialista (2009: 382). Con respecto de Amaya Amador, los críticos literarios reconocen, al igual que en Carmen Lyra (Costa Rica, I887-1949) y en Carlos Luis Fallas (Costa Rica, 1909-1966), ${ }^{4}$ la militancia política en los partidos comunistas de sus países, factor que les proveyó los insumos para lo que escribieron

4 Carmen Lyra (seudónimo de María Isabel Carvajal) y Carlos Luis Fallas fueron escritores costarricenses. Ella publicó en Repertorio Americano un conjunto de relatos acerca de la compañía bananera en la región costera costarricense con el título Bananos y hombres (193I). Fue pedagoga, luchadora incansable por los derechos de la niñez, las mujeres y los trabajadores, militante del Partido Comunista de Costa Rica al igual que Calufa (seudónimo de Carlos Luis Fallas). Él escribió la célebre Mamita Yunai (194I) y lideró el movimiento huelguístico. La mención de Yunai proviene de su novela como forma popular de llamar a la United. 
desde "un impacto testimonial en el texto de la novela, especialmente por medio de los paratextos (prólogos, introducciones, presentaciones)" (2009: 386).

Es homóloga la visión que despliega Pérez Brignoli cuando menciona la vida política de Amaya Amador y Fallas, plasmada en las novelas bajo un "naturalismo costumbrista y la pedagogía revolucionaria” (2018: 464). Pérez Brignoli expresa que en Prisión verde se muestra "la dura vida en las plantaciones y las míseras condiciones de los trabajadores conducían, previa la acción de dirigentes esclarecidos, a un ciclo inevitable de resistencias, huelgas, sabotajes, organización sindical y dura represión, en el contexto de la larga dictadura" (2018: 46I).

Por otro lado, Portillo Villeda plantea una investigación acerca de Prisión verde por el contexto referencial. La autora enfatiza la semantización de campeño, campeña y compañeros acorde con las circunstancias histórico-políticas en un periodo aproximado de diez años en el que las compañías bananeras como la Tela Railroad Company y la Standard Fruit Company hicieron de la costa norte del país su sitio de operaciones comerciales (2OII; I8-I9). Concuerda con Grinberg Pla y Mackenbach (2009) en el análisis que sustenta desde elementos biográficos, casi testimoniales de la vida del autor, reflejados en Prisión verde. Soluri, en el capítulo "Retorno a la Prisión verde" expone una analogía de la situación laboral en los campos bananeros de la costa hondureña con Prisión verde para mostrar la dinámica en la cual vivían y trabajaban los campeños en la región; al respecto, escribe:

La transformación del paisaje de la Costa Norte resultó del trabajo de millares de personas (sobre todo hombres) que despejaron los bosques, cavaron zanjas de drenaje e irrigación, y sembraron, cultivaron y cosecharon el banano (...) Esta multiplicidad de trabajadores migratorios de las fincas, pobres y en gran parte analfabetos, inspiró a Ramón Amaya Amador a escribir Prisión verde, una novela que gira alrededor de las vidas de un grupo de campeños, o trabajadores de las fincas bananeras (Soluri, 2013: 214).

Aguilar Molinari estudia en su tesis doctoral un corpus de la región centroamericana, bajo la premisa de que son producto de la relación entre literatura y la revolución comunista en un periodo de casi sesenta años, para Honduras y Prisión verde destaca:

Una de las primeras críticas (...) va dirigida a la ideología liberal dependiente de los sectores hegemónicos hondureños, que como se ha visto, habían abierto el país a la intervención del capital foráneo con el argumento de que esto mejoraría la situación general de todos los hondureños. Cada personaje sintetiza así un interés 
social general que el texto representa en contradicción. Más adelante en el texto, hace su aparición por vez primera el sector de los proletarios agrícolas, encarnados en la figura de Máximo Luján (Aguilar, 2015: 138).

La revisión de la crítica es consecuente con las obras elegidas, lo que permite examinar, desde otras aristas, la dinámica humana de las relaciones en la que la fuerza laboral en ambientes de condiciones climáticas extremas, bajo el poder de la compañía bananera, tensa los nexos entre iguales, es decir, entre los campeños o trabajadores de la finca bananera y en otros sectores productivos como los obreros citadinos retratados en Destacamento rojo. Dicha tensión luego se disuelve bajo modificaciones en los espacios y en la jerarquía laboral de quienes abandonan a sus compañeros o, en el peor de los casos, finaliza con la muerte.

Ramón Amaya Amador es una pluma reconocida en el ámbito literario hondureño porque destacó con una profusa producción literaria homóloga a su trayectoria política. Nació en Olanchito en I9ı6, falleció en un accidente aéreo en Checoslovaquia en 1966. Destacó en la narrativa con obras como Prisión verde (1950), Amanecer (1953), Constructores (1958), Los brujos de Ilamatepeque (1958) y Destacamento rojo (1962). Anota Albino Chacón fechas póstumas para las siguientes publicaciones “Operación gorila (I970 en ruso; I99I en español); Cipotes (198I); El Señor de la Sierra (1987); Con la misma herradura (1993); Jacinta Peralta (1996); Biografía de un machete (1999); Memorias de un canalla (2004)" (Chacón, 2007: 22). Además, se reconoce su producción literaria en el género cuentístico, en drama y en ensayo.

Prisión verde había visto la luz en entregas del semanario Alerta, en la tierra natal del escritor en 1945. Escrita en un lenguaje llano, relata dos historias paralelas, según mi consideración, en los personajes de Máximo Luján y Martín Samayoa, esto por cuanto, el primero de ellos metonímicamente es la nación hondureña que ve acallada su voz y violentadas sus acciones en procura de mejores condiciones laborales. Samayoa, por su lado, es la representación de quienes, como él, creyeron que al vender sus terrenos a la compañía obtendrían un bienestar económico diluido en la dura realidad de haber sido propietarios de tierras y ahora, trabajadores para la compañía. Con ellos gravita una gama de personajes, algunos estereotipados, otros

5 Al respecto anota Evelyn Uhrhan Irving "Unfortunately, he was killed in an airplane crash while traveling from Bulgaria to Czechoslovakia in 1966, leaving behind some twenty unpublished works" ['Desafortunadamente, murió en un accidente de avión mientras viajaba de Bulgaria a Checoslovaquia en 1966, dejando atrás una veintena de obras inéditas'] (1997: 759). 
no, que contribuyen a ilustrar el mundo de las fincas bananeras desde los procesos de contratación, trabajo en el campo, vivencia cotidiana en los comedores y de las relaciones intersubjetivas establecidas en dichos espacios. La edición revisada fue hecha por la Editorial Universitaria; consta de seis publicaciones; la portada corresponde a la diseñada para la tercera, que fue reutilizada, probablemente, en las que empleó la Editorial Universitaria. ${ }^{6}$ Dividida en 3 I capítulos y una conclusión, es la antesala a Destacamento rojo.

Con un carácter urbano pero sin dejar de lado los nexos con las fincas bananeras en donde se libra la contienda entre empleados y jefes de la compañía bananera, Destacamento rojo, pletórica de personajes, establece relaciones intratextuales con Prisión verde a través de Martín Samayoa, Catuca Pardo, el hijo de ella y Tivicho. No obstante, rescato un personaje central, también reconocido por Umaña cuando acota: "Rotundo es el líder revolucionario, ecuánime, sereno, modelo de esposo y padre, desinteresado, querido por todos, dando una lección permanente ante cualquier situación que se presente, etc." (Umaña, 2003: 209). En Rotundo García, el narrador ha puesto no solo la ideología del Partido Comunista, sino que ha apostado por hacerlo partiendo de que una sociedad hondureña mejor es posible. Para ello, García es el orador, educador y activista en quien la masa trabajadora ha visto reflejada la esperanza de que ese anhelo es alcanzable.

Para el artículo he revisado la edición publicada en México en 1962. Destacamento rojo es una obra extensa, dividida en cuatro partes: Nucleando fuerzas y El Partido tienen II capítulos cada una, Vendaval en mayo (I4 capítulos) y, En la primera línea de la lucha popular (I7 capítulos). Por último, acoto un elemento clave en la relación intertextual e intratextual que acompañan a ambas obras: Becerra en el Prólogo de esta última señala que el escritor olancheño pensó una trilogía novelística acerca del movimiento social asociado al enclave bananero en Honduras, cuyos títulos en

6 Para consultar las diversas ediciones y portadas de las novelas, véase la página web https://www.ramon-amaya-amador.com. De dicha página rescato las fotografías para Prisión verde y Destacamento rojo incluso en impresiones china, alemana y checoslovaca. Sobresalen dos detalles, el primero de ellos es que los libros en sus forros emplean indistintamente el nombre del escritor en letra minúscula, así como el de los títulos de las novelas. México y Argentina son los dos países en los que Amaya Amador publicó debido a las circunstancias de persecución de su obra literaria; ese es el segundo detalle. Dejo abierta la posibilidad para un estudio semiótico de las portadas de las novelas en un futuro; es un campo rico en posibilidades de estudio para determinar la línea que el escritor siguió en sus obras en cuanto a aspectos estéticos paratextuales que acompañaron sus luchas no solo políticas, sino también literarias y de publicación. 
orden de publicación serían Prisión verde, Rieles gringos (a la que denomina inédita) y Destacamento rojo. ${ }^{7}$ También Yúdice coloca en una lista la obra de Amaya Amador junto con otros exponentes; él la llama novela representativa de las Repúblicas Bananeras. Indica para el caso del escritor hondureño, Prisión verde, Destacamento rojo y Rieles gringos, estas dos últimas en el año 1967 (Yúdice, 2010: 99).

Con respecto de la desaparición de Rieles gringos me apoyo en las siguientes hipótesis. Becerra menciona que el escritor "se ve obligado a desistir de enmarcar en una trilogía estrecha lo que es fuente inagotable de creación (...), y en consecuencia prefiere ampliar y modificar con otras nuevas obras el proyecto inicial, reiteradamente anunciado al público lector" (Amaya, 1970, Prólogo, párr. 2). No obstante, suponemos que debido a la copiosa actividad de escritura, según Becerra en el Prólogo de Prisión verde de I990 "Este trabajo le consumía al novelista de tres a cuatro meses, por lo cual Ramón Amaya Amador escribió hasta tres novelas por año" (1990: 7), conjetura que nos lleva a valorar que entre la publicación de una y otra sí existió o existe la obra Rieles gringos. ${ }^{8}$ Algunos argumentos por considerar serían efectivamente esa capacidad prolífica de escritura, así como las movilizaciones geográficas a las que se vio obligado el autor (Guatemala en 1947, Argentina en 1954 y Checoslovaquia en 1959), que marcaron su transitar político-ideológico.

Otras razonamientos serían que si Prisión verde es la primera novela de la trilogía, en un promedio de dos a tres años de publicación, Amaya Amador pude tener escrita pero inédita Rieles gringos en 1953, aproximadamente. Un año después, Gua-

7 Becerra había presentado la mayoría de los prólogos de la novela; la excepción la posee Amaya Fúnez en el año 2004 para la cuarta edición mexicana. Becerra escribió el Prólogo de la edición que revisamos (1962); también se hallan la primera edición hondureña pero la segunda ejecutada correspondiente a I98I; por último, para la tercera da cuenta Amaya Fúnez cuando explica que se había agotado rápidamente (https://www. ramon-amaya-amador.com/index.php/obras/prologos/ıoo-destacamento-rojo-prologo-4-edicion, Introducción, párr. 2; consulta: 23/11/2019).

8 Josué Joel Sevilla López señala con respecto a Rieles gringos: "existen dos versiones. La primera versión yo la denominaría una versión tradicional que fue alimentada por el escritor Longino Becerra. [Él] tuvo acceso al archivo de Amaya Amador luego de él haber muerto (...) Rieles gringos (...) la coloca como una novela desaparecida, pero sí mencionada en el diario de Ramón Amaya Amador". La segunda versión es aquella en la que Sevilla López señala como supuesto dueño del legado de Amaya Amador a su hijo Carlos Amaya Fúnez, "él maneja el archivo, él fue el que recuperó el archivo de Ramón Amaya Amador padre, que quedó allá en Checoslovaquia, entonces algunas personas piensan de que posiblemente exista una copia (J. J. Sevilla López, comunicaciones personales, 22 de octubre, 2019). 
temala sufría el golpe de Estado contra Juan Jacobo Arbenz, hecho que desplazó al escritor a Argentina, y con dicha movilización, sus obras inéditas y materiales. En fin, sirvan las argumentaciones para consolidar al interior del estudio, las presuntas conexiones que pueden haber entre Prisión verde y Destacamento rojo y estas con la obra Rieles gringos.

Entre Prisión verde y Destacamento rojo median 17 años. Para comprender el peso que mayormente asume Prisión verde en la crítica literaria hondureña y foránea es válido sopesar que aunque la primera fuera escrita en 1940 había circulado, según acota Umaña (2003: 195), en formato de entregas en un diario local, lo cual representa una forma de acercamiento popular: más leída y considerada como una de las obras cumbres en la narrativa hondureña:

No sólo [sic] representaba una realidad conocida por todos, sino que verbalizaba una condenación colectiva en contra de las ofensas que se inferían a los trabajadores y - posiblemente lo más importante- aportaba una esperanza, por medio de la organización y consiguiente lucha de los trabajadores en dirección a la reconquista de sus perdidos derechos (Juan Ramón Martínez, citado en Aguilar Molinari: 150).

Destacamento rojo, por otro lado, fue publicada en forma póstuma por las circunstancias que rodearon la muerte del escritor. Que se halle alejada cronológicamente del movimiento social retratado en Prisión verde es quizás una razón para que la crítica literaria, su estudio y análisis no fueran tan profusos. Sevilla López menciona "el gran pecado de Destacamento rojo fue nacer en una etapa de anticomunismo en la década de 1960, y ser una historia novelada del Partido Comunista de Honduras (РСH)" (2OI9: 4).

\section{En este barracón no hay "orejas"}

Con el título anterior tomado de Prisión verde se reconoce el espacio en que habitaban los empleados de la compañía. Soluri menciona: "Durante la primera mitad del siglo $\mathrm{xx}$, las subsidiarias hondureñas de la United Fruit alojaban a los trabajadores en barracones de madera de seis habitaciones" (2013: 247). En esas habitaciones cuyas condiciones eran antihigiénicas, insalubres y con hacinamiento, dormían, descansaban y hacían vida cotidiana.

La educación revolucionaria, término usado por Pérez Brignoli (2018), se alcanzó en las fincas bananeras durante la época retratada en el corpus y fue posible por sitios como los barracones, en los que, al calor de escasas velas, luego de jornadas 
extenuantes de trabajo y con temor de ser escuchados, líderes como Máximo Luján y Rotundo García desempeñaron tareas de enseñanza y formación colectiva. Es entonces que en este primer apartado de análisis surgen dos horizontes para comprender el sentido colectivo del movimiento social de los empleados de la compañía y de quienes se les oponen. Resulta representativa la unidad y la colectividad que, al calor de las circunstancias laborales temporales, se contraponen a la referencia de Sartre, quien señala que la relación con el otro "es conflictiva" (Bubnova, 1997: 264), no así para Bajtín, porque edifica.

Luján en Prisión verde y García en Destacamento rojo son los líderes, quienes desde su formación política, ideológica y de mundo de vida, se erigen a la cabeza de los movimientos sociales en las obras. Alrededor de las figuras masculinas gravita la colectividad campeña que oye los discursos construidos desde sus saberes, desde las necesidades y las exigencias que intuyen colectivas; también están quienes los abandonan por no avizorar respuestas a las situaciones laborales a corto plazo, o por ver frustrados sus sueños inmediatos de estabilidad económica.

Los espacios geográficos definen las tareas y la población elegida. García en el Progreso y otros lugares más urbanos y Luján en Culuco (sitio de la plantación bananera retratada en Prisión verde) se toman su tiempo para formar a sus compañeros de trabajo. En épocas duras de lluvia en las cuales las faenas se ven detenidas en las plantaciones, Luján aprovecha para leer, dialogar con los compañeros y, de paso, generar una empatía por la causa social:

Con el transcurso de las noches, el número de oyentes aumentó. La mayoría de "veneneros" iba al cuarto de Máximo, deseosa de oír, aunque fuese desde el corredor del barracón, lo que adentro se leía. Ahora nadie protestaba; antes bien, apenas regresaban de las fincas y comían, ya estaban reclamando las lecturas (PV: I45). ${ }^{10}$

Con García sucede lo mismo: en su desplazamiento geográfico (de la ciudad a la costa) es manifiesta la labor de convencimiento y educación ideológica que el líder

9 Con respecto a ambos personajes, acota Umaña: "Máximo, el personaje cuyo nombre alude al desarrollo de una calidad humana en grado máximo" (2013: 197). Para Destacamento rojo, observa "En algunos momentos, la novela deviene en auténtico panegírico para el dirigente cuyo nombre alude, justamente, a la rotundidad, a lo definido y definitivo de su personalidad" (2013: 209).

${ }^{10}$ Empleamos las ediciones consignadas en la Bibliografía. Para cada obra hemos anotado las iniciales del título (Prisión verde PV y Destacamento rojo DR) y la página correspondiente. 
logra. Destacamento rojo condensa con un sentido global el movimiento huelguístico del año 1954 y lo hace con sujetos que confluyen desde sectores laborales heterogéneos. Es por lo anterior que la movilización de García inicia en San Pedro Sula, continúa en Progreso, Tela, Puerto Cortés, entre otros. Él, al igual que Luján, es esperado en los lugares a los que llega, la masa trabajadora ve cristalizado en su retórica y en su presencia el panorama de un mejor futuro "Desde el día en que Rotundo García llegó a Progreso con sus compañeros, la huelga tomó carácter más ordenado" (DR: 193).

Dichos protagonistas destacan en las obras de Amaya Amador por la sencillez que acompaña sus presencias, el discurso llano y la capacidad de movilización que lograron entre sus semejantes; sobresale en Luján, quien es observado por el maestro Damián Cherara: "Damián, frecuentemente, se preguntaba cómo era que Luján, fruto de aquella vida tormentosa, sin haber recibido educación, tenía tanta claridad en sus razonamientos, en la captación de los problemas, en la búsqueda de soluciones" (pv: 145). Este personaje, al igual que García, se ha vinculado con el mundo laboral desde sus propias experiencias y aprendizajes, ha proyectado su yo (Bubnova, 1997: 263) desde el mundo de las plantaciones bananeras y, en consecuencia, ha asumido un proceso edificativo de sus subjetividades.

García contrasta con Luján en cuanto a la formación que le precede: "extrabajador del ferrocarril, maestro de enseñanza primaria, exredactor de Vanguardia periódico oficial del PDR ${ }^{11}$ y dirigente del movimiento democrático en la costa norte" (DR:25). La crítica de Grinberg y Mackenbach redirecciona que en las manos de los protagonistas masculinos se asume la construcción del Estado-nación porque "Todas las novelas [en el marco del corpus que revisan los críticos] coinciden en privilegiar la mirada de sujetos de género masculino, generalmente blancos o mestizos. La perspectiva de esos hombres blancos o mestizos será constitutiva, en muchos de los casos, de los otros sujetos representados en las novelas" (Grinberg y Mackenbach, 2009: 39I).

La cita textual anterior homologa la (re)construcción ideológica-revolucionaria de la nación hondureña mostrada en el corpus, concebida además como renacimiento político en una nación desgastada por tiranos, pero en esta ocasión en el siglo xx, renovación también del Partido Comunista Hondureño. En las novelas, las caracterizaciones saltan a la vista cuando se reconocen protagonistas masculinos como cabecillas; en ellos el logos y la acción los erigen como figuras de poder con capacidad para la movilización social y sindical. Otros personajes se pliegan a

11 Partido Democrático Revolucionario. 
ellos, es un acuerpamiento de los semejantes considerados sin voz, débiles como las mujeres y los niños (Catuca Pardo y su hijo en Prisión verde), los adultos mayores (don Braulio en Prisión verde), las minorías étnicas (indígenas y afrodescendientes como la familia de Tovico Loreto en Destacamento rojo) bajo una figura patriarcal, casi redentora que condensa el malestar colectivo de las clases más desfavorecidas. El caso es que en las acciones de los héroes se perfila semánticamente la actitud de solidaridad por sus semejantes.

El segundo escenario es el que estudia Mackenbach (2006) en un artículo antesala del escrito con Grinberg Pla (2009). Argumenta que la narrativa bananera culmina, producto de líneas literario-estéticas, con el testimonio en la región en la segunda mitad del siglo pasado:

la oralidad en la novela de plantación bananera introduce, desde nuestro punto de vista, constantes para la configuración posterior del género testimonial. Queremos plantear que esta forma narrativa presenta ya ciertas constantes que posteriormente, en conjunción con otros elementos caracterizarán las formas estéticas del género testimonial en Centroamérica (María Salvadora Ortiz citada por Mackenbach, 2006: 130).

Tampoco se distancia Portillo Villeda en esa argumentación, cuando anota en el marco referencial de Prisión verde esta línea de pensamiento:

Contemporary historians' use of oral histories gathered from workers has been influenced by the literary tradition of the social realist novels set in the banana regions of Central America. Many of these books were the work of authors deeply committed to the working classes, who strove in their fiction to make connections between the living conditions of banana workers and a national reality [El uso que los historiadores contemporáneos hacen de las historias orales recopiladas de los trabajadores ha sido influenciado por la tradición literaria de las novelas realistas sociales ambientadas en las regiones bananeras de Centroamérica. Muchos de estos libros fueron obra de autores profundamente comprometidos con las clases trabajadoras, que se esforzaron en su ficción por hacer conexiones entre las condiciones de vida de los trabajadores bananeros y una realidad nacional] (Portillo, 20II: 27). 
Pues bien, con esas bases es viable reconsiderar elementos compartidos en ambas manifestaciones estético-literarias (la novela bananera y el género testimonial). ${ }^{12}$ Con Bajtín (1998: 19I) coincidimos en la refracción de fuerzas vivas en donde la colectividad se hace presente desde las obras literarias; dicho punto de refracción (para emplear los términos bajtianos) son entonces Luján y García; en ellos han confluido las necesidades que circulan en el espacio, que no han sido llevadas a un punto angular en el que se logren concretar y proyectarse con la suficiente fuerza. En los discursos de Luján y García están acalladas las voces de sus semejantes y la polifonía de la nación en su condición extrema de miseria, en la que la movilización social por razones laborales agrupa a un sector considerable.

En los dirigentes se ha volcado la representación de la patria sencilla, autodidacta la mayoría de las veces, esforzada y con pensamiento lúcido; ellos, por su parte, solo pueden contribuir "desde abajo" a rescatar lo perdido en la vorágine capitalista del enclave que ha desechado recursos humanos, materiales y territoriales; cierto deber moral que han construido desde los espacios comunes y aparentemente solidarios los empuja a acometer las causas. Al respecto la idea de nación se solidifica con Grinberg y Mackenbach (2009) cuando aluden: "Así, las bananeras son concebidas como espacio integral de la nación" (2009: 382), en cuyos territorios hay tiranías que pueden derrocarse con la fuerza comunal.

Con Doris Sommer (1992), siempre en el hilo del género testimonial, conjuntamos estas otras posibilidades en la visualización de los protagonistas dirigentes:

Solo para ahondar en esas consideraciones asumimos dos admisibles razonamientos. En el testimonio "Su unidad narrativa suele ser una 'vida' o una vivencia particularmente significativa (situación laboral, militancia política, encarcelamiento, etc.)" (Beverley, 1987: 9), pero en la narrativa bananera sobresalen, particularmente como lo anotan Grinberg y Mackenbach, las militancias políticas de algunos escritores; uno de ellos, por ejemplo, Amaya Amador. Quizás al colocar un velo se ha manifestado en la presencia del personaje protagonista, militante y trabajador, pero no en la del narrador. Al respecto, con Mamita Yunai (I94I) de Carlos Luis Fallas, los críticos señalan que el autor por función metonímica es también el narrador/protagonista que "funciona efectivamente como representante y polo de identificación de toda una clase social, contribuyendo por medio de la literatura a la construcción imaginaria de un sujeto colectivo del cual forma parte: la clase proletaria" (Grinberg y Mackenbach, 2006: 166). Ambas producciones literarias son emergentes, a propósito puede leerse: "el testimonio es una 'narración de urgencia' que nace de esos espacios donde las estructuras de normalidad social comienzan a desmoronarse por una razón u otra" (Beverley, 1987ः 9); el enclave bananero trastornó espacios, alteró climas, modificó y corrompió sistemas políticos ya débiles. 
I. Tanto Luján como García son sujetos que desde una pluralidad se afianzan en la contigüidad, es decir, no sobresalen por sobre otros, están con ellos y asumen que la lucha para la cual han sido destinados es la de la nación. Es una (re)invención, en el siglo en que fueron escritas las novelas, de una acometida rebelde de los indígenas, los mestizos y la clase obrera frente al pulpo extranjero. En boca de Luján leemos "Nuestro dolor es igual al dolor de los trabajadores urbanos: explotados somos aquí y explotados son allá" (PV: 49). El sentido de colectividad permea también estas frases de García:

Precisamente quienes le hacen justicia somos nosotros, la clase obrera revolucionaria. Nosotros hemos recogido el legado del gran Paladín [refiriéndose a Morazán] y luchamos por la misma causa, sólo que en otras condiciones: por la independencia nacional, la unidad de nuestro pueblo, contra el coloniaje (DR: 37 ).

El empleo de la primera persona plural en boca de los personajes, como anota Sommer, no hace sino reforzar "la metonimia, un movimiento lateral de identificación mediante relación, [en que se] reconoce la posible diferencia entre 'nosotros' como componentes de un todo descentralizado" [el destacado es del original] (1992: 144). A lo que se enfrenta el líder es al señalamiento de un sistema social que ha carcomido la nación. Su fuerza no puede limitarse a reconocerlo, es su deber patriótico comunicar esa situación desigual en la que se encuentra con sus semejantes.

2. Compartir y concientizar son otras funciones de los protagonistas. Para eso, ambos individuos son el producto de una formación autodidacta el primero, y maestro el segundo. Están constituidos para llegar al pueblo, porque "mientras la autobiografía habla por los lectores, algunos testimonios logran la modestia de hablar a los lectores" [el destacado es del original] (Sommer, 1996: 145). El caso es que lo hacen desde voces y actitudes patriarcales:

los campeños no hemos perdido hombría. Lo que sucede es que hemos aprendido mucho, sobre todo a conocer que la violencia sola es mala consejera. Nada bueno producen las hombronadas sin ton ni son. Tú recuerdas tus tiempos y a muchos hombres machos; ahora, dime: ¿qué hicieron por ellos y por los demás? ¿A dónde están por su hombría individual? (pv: 47).

Con ellos viene un sistema patriarcal que no solo afianza una educación revolucionaria con la lectura, el análisis de textos teóricos, panfletos, propaganda y discusiones en pequeños grupos, sino que los consolida en la labor emergente; Luján en un 
acto identitario y de paso representativo del movimiento, reconoce que ya sabía lo que lee en los textos "Recibía el periodiquito y algunos folletos, los que leía con detenimiento y gran satisfacción porque iba encontrando allí ideas que eran suyas desde largo tiempo, lo cual le confirmaba que su camino era correcto" (pv: 144). Con formación más profunda, García es quien escribe: si Luján lee a la luz de un candil en tiempos de lluvia en los barracones, Rotundo García escribe como un intelectual orgánico, se le reconocen el orden y la formación como valores en su carrera política.

3. En Prisión verde Luján era venenero, ${ }^{13}$ mientras que a García en Destacamento rojo se le anotan empleos como ferrocarrilero y maestro. Desde esos sectores laborales, el "yo" que emana de sus diálogos viene acuerpado por la forma pronominal "nosotros". Sirva esta cita como ejemplo:

la crítica de Máximo no va dirigida contra las entidades explotadoras como la Compañía o el Estado, sino más bien sus destinatarios son sus pares, sus compañeros de trabajo y de vida. El lugar desde el que piensa Luján es algo así como un sitio post-ideológico a partir del cual es posible observar críticamente el comportamiento ideologizado de sus compañeros, en otras palabras, Máximo se pregunta si alguna vez llegará a ser posible que su percepción de la realidad y de sus posibilidades no sea tan solo un deseo utópico aislado y doloroso, sino que sea la forma práctica de las relaciones humanas. El personaje se interroga entonces si alguna vez sus compañeros proletarios se le unirán en ese sitio post-ideológico desde el que él mismo observa la vida transcurrir (Aguilar, 2016: 143).

Los dirigentes coinciden en venir de espacios comunes, de experimentar las mismas situaciones de quienes los acompañan. Estando dentro de esa comunidad obrera, Luján duda acerca de sus semejantes, mientras que García, más fuerte en sus convicciones, con más recursos humanos, materiales e ideológicos proyecta un horizonte diferente en la renovación política de la nación.

Venenero es aquella persona encargada de regar con una máquina rudimentaria (por lo general, con un aspersor) las plantas con un veneno (es la forma popular empleada en Prisión verde para denominar el herbicida). Esta ocupación particular es para atacar el avance de la sigatoka, que es producida por un hongo cuyos efectos son la reducción en el rendimiento de las plantas. A Centroamérica llegó aproximadamente en la década de los treinta (PV: 59-62). 


\section{“., para que no sirvan de rompehuelgas”}

Si en el anterior subtítulo hemos explicitado a los protagonistas líderes desde diversas dimensiones, así como a quienes se hallan con ellos en el proyecto de renovación obrera y nacional, es tarea ahora distinguir quiénes son los antagonistas. En lo que respecta a personajes, "algunas novelas propondrán la existencia o bien la necesidad de identidades colectivas, en tanto que otras únicamente giran en torno a identidades individuales" (Grinberg y Mackenbach, 2009ः390). En estas últimas, los narradores han proyectado lo que no son Máximo Luján ni Rotundo García. Es decir, la otredad, aunque en momentos iníciales los acompañaron, han dejado ahora las filas para caer del otro lado. En Prisión verde:

la trama gira en torno de las distintas víctimas de la compañía bananera, en un intento por crear una identidad colectiva para todos los explotados y si se destaca un personaje como Marcos, es por su carácter de antihéroe, antítesis del personaje modelo -Máximo Luján (Grinberg y Mackenbach, 2009: 391).

Marcos Palomo encarna el machismo y la violencia, antagónico a Luján y a los campeños en la plantación. Sus palabras se extrapolan a las acciones que emprende con rabia, con un machismo evidente arremete contra las mujeres a las que visualiza como objetos. Es la representación del parecer frente al ser: "El Capitalino, como le llamaban algunos por su procedencia, tenía fama de irresistible Don Juan, y él, sabiendo esa notoriedad, la explotaba con vanidad jactanciosa" (PV: 55).

Destacamento rojo posee más personajes antagónicos a García. Conjeturamos que la vida pública llevada por el dirigente, la trayectoria por distintos sectores laborales y geográficos más la tarea formativa, han contribuido para que una mayor cantidad de individuos sean la alteridad. Destacan estadounidenses a la cabeza de la compañía (el gerente, el secretario mister Bell, mister Halter), autoridades policiales y militares (coronel Obricida), medios de comunicación como la prensa (Ruibarbo, Tupho D'Oscariote) y sus mismos compañeros militantes de las organizaciones comunales (Tadeo Violencia, Paco Encino, Salvador Prieto). Sin embargo, por la cercanía y la relación de semejanza, como partidarios y trabajadores, la alteridad salta a la vista cuando de dinero se trata; es por eso que nos centraremos en la descripción solo de quienes inicialmente acompañaron a García en la conformación de las organizaciones y la reunificación del Partido Comunista Hondureño. Para Luján, en Culuco (sitio de la plantación bananera), cuyo punto es más limitado 
tanto en lo geográfico como en la formación revolucionaria emprendida, la otredad es presentada en la figura de Palomo.

Los antihéroes en Destacamento rojo oscilan en caracterizaciones sencillas; no hay profundidad en el abordaje hecho por el narrador; solo se reconocen Paco Encino y Salvador Prieto "y tantos otros que llegaron en los últimos momentos para ayudar a dividir el movimiento y ponerlo a merced de la empresa” (DR: 242). En ellos hay ausencia de rasgos que determinen una personalidad sólida; en el plano enunciativo no ocupan mérito en la novela; vedados de la palabra, solo sus acciones desleales cuentan para ambos bandos. La excepción es Tadeo Volencia quien, alcohólico, lleno de envidia y rencoroso, no encuentra porvenir satisfactorio en ambos bandos pues:

sigue una táctica bifacética. Cuando está con los trabajadores es un ferviente revolucionario y habla pestes de los imperialistas y del gobierno lacayo. Cuando está con los jefes o sus servidores, es un reformista defensor del «Presidente en mangas de camisa» y de los civilizadores gringos (DR: I7I).

Es este último quien se asemeja en el comportamiento a Marcos Palomo. Inicialmente habían militado y creían en la fuerza del movimiento, luego dan un giro en el corpus como personajes frontera. Gaínza lee la otredad desde la semiótica, esta "consiste tanto en el reconocimiento de lo distinto, extraño, raro, ajeno o diverso, como en la consolidación, si no legitimación, de la conciencia de identidad" (Gaínza, 1994: 15). El poder, el dinero fácil, la aceptación y el machismo convierten en volubles las identidades de los personajes más violentos, con caracteres irascibles y con precipitación tanto en el nivel verbal como en los actos. No poseen la autenticidad consolidada en años de estudio, en situaciones de injusticia social vividas en carne propia o las asumidas por función metonímica de Luján ni García. Son personajes legitimados en las novelas de Amaya Amador, frente a las identidades débiles de sus contrarios, constituidos semánticamente con más y mejores adjetivos y verbos de acción frente a sus pares antinómicos (Gaínza, 1994: 17).

Además, en los espacios intersticiales o fronterizos de las personalidades de Palomo y Volencia, entre el ser/parecer/hacer, los narradores han construido visiones endebles de estos. Son, en la patria pequeña, aquellos traidores más inmediatos de ser comprados por el sistema de dominio del enclave:

Marcos, que los conoce a todos, que fue uno de los primeros instigadores a la protesta, es el encargado de las eliminaciones, el que va señalando uno por uno a los 
trabajadores más rebeldes y sinceros. Comienza así, su nueva labor, con la traición y la iniquidad (PV: I89).

El dinero es el acicate de las delaciones, seguido del afán por el poder político; el primero sirve para alardear junto con los administradores de las plantaciones "dirigiéndose [Marcos Palomo] a unos campeños que han llegado a buscarles, en cuanto les vieron, invita: ${ }_{i}$ Vengan, mis muchachos, acérquense! Tomaremos primero guaro" (PV: 218). Paco Encino posee otro objetivo que cristaliza más tardíamente cuando "se hizo liberal a la sombra protectora de un caudillo local que era de los integrantes del pun. ${ }^{14}$ Para las elecciones que se celebraron más o menos libres, no le habían cumplido la promesa de la diputación" (DRः 333). De Salvador Prieto casi no se menciona su presencia y sus acciones, solo que acompaña en los excesos alcohólicos a Volencia codeándose en un sitio exclusivo para altos gerentes y empleados estadounidenses de la compañía en San Pedro Sula: "Las atenciones de los gringos y sus empleados para los ahora miembros del $\mathrm{CCH}^{15}{ }^{15}$ no tienen límites. Todo lo otorga la empresa en aras del buen entendimiento" (DR: 25I).

En una lectura global puede hallarse en el corpus que quien traiciona la movilización social tan esperada de los trabajadores en la ciudad y los campeños en las plantaciones bananeras está cometiendo además traición contra la patria pequeña (la instaurada por el enclave), y luego la nación es el sema predominante de la fidelidad por el movimiento frente al perjurio que se extiende no solo al ámbito de los compañeros de labor, sino que por metonimia es Honduras. En Destacamento rojo el empleo de la violencia para evitar el abandono de las filas durante la huelga es extremo: "Pero los estibadores hablan, discuten, convencen a muchos hombres para que no sirvan de rompehuelgas porque todos son hermanos de infortunio. Los que no aceptan razones son convencidos a puntapiés" (DRः I77). Subyace en esa operación un acto machista impositivo de la fuerza bruta como recurso final.

Del mismo modo la expulsión de las organizaciones obreras en Destacamento rojo es la pena por la deslealtad al movimiento; en Prisión verde, la ausencia de la solidez sindical no castiga a Palomo. El caso de Paco Encino ilustra mejor ese acontecimiento:

había actuado en la huelga como un oportunista, actitud que fue investigada por el Partido. Ricardo Trigo había sido uno de los integrantes de la comisión investigadora

\footnotetext{
14 Partido Unión Nacional.

15 Comité Central de Huelga.
} 
enviada por el buró político, y habían comprobado su deslealtad. Encino, malaconsejado por su propia consorte, se rebeló contra el Partido y fue expulsado (DR: 333).

Aunque no sea motivo de análisis, sí es una lectura válida reconocer que en ambas novelas se manifiesta la otredad de género porque los discursos y las actividades son emprendidas por hombres como (re)constructores del país. El logos, el discurso emana de voces masculinas, de unas incluso superiores a otras. Con Paco Encino, cabe abrir un paréntesis para sustentar dicha afirmación. Nótese que quien motiva el cambio de actitud dentro del Partido en el caso de Encino es su esposa. La razón es una: el deseo por sobresalir del ámbito económico en que se encuentra el núcleo familiar, por lo que arguye que si él acepta el ofrecimiento para ser congresista por el Partido Liberal de Honduras con la candidatura de Ramón Villeda Morales, nuevas posibilidades se despliegan “ ${ }^{\prime}$ Entonces nuestra felicidad será completa, Paco! ¡Nos iremos a vivir al centro! ¡Dejarás de trabajar como obrero, serás un personaje estimado en la alta sociedad y tu mujercita podrá presentarse como una reina dondequiera, sin vergüenza y sin humillaciones" (DRः240). Se reconoce el cuestionamiento de la masculinidad de Encino "Cora, su esposa, no es que sea una mujer mala, pero lo hace dar vuelta y media por nimiedades. Prácticamente ella lo domina y lo hace ir para donde ella quiere" (DR 28 ). Con esas palabras de Dalia, la esposa de García, se sustenta otra constitución semántica en la fuerza masculina patriarcal que sostiene el movimiento en oposición a la debilidad, que en una interpretación y lectura desde la teoría de género, no hace sino reforzar la idea de que los que abandonan la lucha son comparados con las mujeres en menosprecio de la dignidad humana e individual.

Una forma de socialización en la que los jerarcas de la compañía consolidaban los tratos hechos con los "rompehuelgas" consistía en abrir el acceso a sitios vedados por ser exclusivos de los foráneos. Las invitaciones, los agasajos y los brindis son hábitos comunes, que sean vistos con altos mandos de la compañía, consumiendo licor y acompañados de mujeres es, a los ojos de personajes como Palomo, Volencia y Prieto, un ascenso. Estar al mismo nivel de quienes en un primer momento fueron sus superiores se traduce en aceptación social, pero también en menosprecio de sus semejantes; al respecto, sirva para ejemplificar la aparente cohesión social lo que refiere Bubnova cuando escribe "Los lugares que yo y el otro ocupamos en el espacio no son simétricos ni iguales" (1997: 264). Desde el punto de vista de quienes reconocen una deslealtad, es el fin de los nexos que tuvieron en el movimiento social. Posas sostiene que en el plano nacional "no es irrazonable pensar el fenómeno de la economía del banano como una lógica parasitaria del capital transnacional en el 
cuerpo de los Estados-nación centroamericanos. Por supuesto, un parásito que fue invitado por las clases dominantes de los respectivos países" (2015:99).

Los discursos, las actividades con fines diversos y los posicionamientos modificables se traducen en las cambiantes intersubjetividades de los individuos; es lo que Gaínza denomina la dialéctica de la otredad (1994: 17) por cuanto pueden reconocerse márgenes en los que Luján y García llevan consigo la metonimia de la nación, incluidos sus compañeros inmediatos en las figuras de Palomo y Volencia, la patria misma y la compañía que, de paso, se halla más lejana a los líderes por ser foránea. Esta acuerpa como seres inmediatos a los personajes que, casualmente, ocupan puntos medios, nunca de líderes en ese sistema de enclave (Palomo y Volencia). La compañía aleja a Luján y García; la nación, por último, es generadora de interés en cuanto se usa, se gasta y se desecha.

La compañía bananera es la entidad instituida como la única ganadora de un juego que hábilmente supo dominar desde sus inicios: explota a Honduras como marco referencial del corpus, a sus ciudadanos, y confabula con los débiles (antihéroes); la nación/patria convertida en bien de consumo es objeto maleable para esta última; Aguilar comenta con respecto a Prisión verde, válido para Destacamento rojo también:

Lo que hace el texto es explicar que el desarrollo de la producción agrícola es en esencia un producto del trabajo humano, pero del trabajo humano alienado, por cuanto los beneficios de este trabajo no son propiedad de los trabajadores, sino de una entidad externa parasitaria, en este caso, la Compañía bananera (Aguilar, 2015: 139).

El Coronel Madero merece atención aparte. En las primeras páginas de Destacamento rojo se le encomienda asesinar a Rotundo García, pero no lo hace. El narrador explica un proceso dual en el que cree reconocerse el coronel, que lo empuja a formar parte de la contienda armada en la montaña junto a un pequeño grupo. Madero fallece en una emboscada, su cuerpo yacerá en la montaña (como el de Luján en las plantaciones). La relación de los acontecimientos queda en la memoria de Loreto, quien tiene como tarea compartir el gesto heroico.

No es casualidad que la muerte además acompañe a los personajes que se han opuesto a Luján y a García. Con esta se cierran los ciclos vitales y humanos de las relaciones que los protagonistas han librado con sus semejantes. Palomo fallece en el descarrilamiento de un motocarro, pero antes ya ha purgado con cierto cargo de conciencia el asesinato de Luján: "Lucio Pardo que, con los brazos cruzados sobre el pecho, ve agonizar a Marcos" (PV: 23I); en Destacamento rojo, Volencia corre igual 
suerte en manos de los agentes de la compañía, quienes "lo empujaron a un absurdo levantamiento que lo llevaba a él como cabecilla. La misma noche lo liquidaron" (DR: 277). Encino, en un estado etílico elevado, protagoniza un intento de suicidio y decide lanzarse de un balcón, acción frustrada porque logró sobrevivir. Briones huye despavoridamente y no es nombrado más en la novela; todo acontece el 2I de octubre (sin mención del año, pero se reconoce el de 1956), fecha del golpe de Estado contra Julio Lozano Díaz por parte de la Fuerzas Armadas. Puede leerse que quien traiciona los más altos valores como la justicia, la equidad y la reconstitución del tejido social termina mal; las experiencias que han marcado la relación de alteridad devienen en lecciones de vida, tanto para la individual como la colectiva.

\section{Conclusiones}

Prisión verde y Destacamento rojo de Amaya Amador dan cuenta de una línea narrativa cuyo referente se halla en poco más de dos décadas del proceso productivo que colocó a Honduras como el mayor exportador de banano de la región y que, de paso, permitió consolidar "un criollismo" (Umaña: 2003) literario aún presente en el siglo xx, con presupuestos estético-literarios rastreables en el género testimonial. Sus líneas narrativas no solo han retratado los sembradíos de banano, sino que también ilustran subjetividades que se cuelan entre las escasas posibilidades de una vida mejor para la nación.

La visión de la alteridad expuesta en este análisis ha abierto el camino para reconocer que, en el corpus, los protagonistas a quienes se les adhieren seguidores en la lucha por la (re)cuperación de sí mismos como seres dignos, de los bienes territoriales y de una autonomía como sinónimo de identidad nacional son la nación misma. Por su lado, descuellan antihéroes que obstaculizan el bien común deshecho por el pulpo extranjero. Así funcionaron entonces las redes de corrupción que en los enclaves bananeros evidenciaron la traición de quienes (como los personajes estudiados en el artículo) revelaron informaciones, fueron cómplices en crímenes, negociaron desde sus mezquinos intereses o delataron a líderes sindicales en aras de lo que creyeron efímera dignidad; no es sino una estructura dialógica compleja (Bubnova, 1997: 260) en la que descollaron unos por sobre otros. Las dictaduras del istmo centroamericano en los años venideros (décadas del setenta al ochenta) ya tenían una base en cual asentarse con la fuerza posible para contribuir a la polarización social y al terrorismo de Estado. 
Los héroes como voces conscientes procuraron, en la medida de lo posible, desplegar con acierto el movimiento que tenían entre manos. Esto refuerza la visión dialéctica que como puente tiende a mostrar a aquellos antagonistas sin una consecución de metas y objetivos claros. Al respecto cabe hacer la acotación de que los narradores, en el corpus, acertadamente emplearon los discursos narrativos con una visión antinómica: los adversarios, tanto en sus discursos como en sus acciones, son vaciados de contenido frente a lo que alcanzaron los cabecillas del movimiento.

No es casual que muera Máximo Luján pero que Rotundo García, por la gracia del coronel Madero, sobreviva, para que este finalmente sea el sacrificado en la lucha armada por el movimiento. En la relación intratextual se reconoce una idealización del espíritu humano y del sistema mismo (castrense, en este caso) concretada en la imagen del militar que no mata a García, aunque sí se cobra la vida de Luján en manos de la alianza manchada por la corrupción del sistema político y la compañía bananera. Lo anterior puede vislumbrarse en función también intratextual de que si en Prisión verde es asesinado Luján, García no puede morir porque con él se acallarían las fuerzas vivas que pugnan por ser escuchadas y atendidas. Simbólica y cronológicamente, los puntos angulares, concebidos en los cabecillas de la lucha obrera, no mueren: uno sucedió al otro en una nueva lucha social.

\section{Reconocimientos}

Agradezco enormemente a Ana Suyapa Dilworth Ordóñez, profesora del Área de Letras de la Universidad Nacional Autónoma de Honduras (UNAH) en Tegucigalpa, las alianzas librescas que me permitieron tener acceso a la obra de Ramón Amaya Amador, igracias amiga y colega! Asimismo, a Josué Joel Sevilla López, del Departamento de Ciencias Sociales de la Universidad Nacional Autónoma de Honduras (UNAH) en el Valle de Sula, por sus comentarios y por compartir su trabajo inédito.

\section{Referencias bibliográficas}

Aguilar Molinari, Gerardo

2016 Comunismo y Literatura en Centroamérica: tres fantasmas en el siglo revolucionario 1932-1990, tesis de doctorado presentada en la Universidad de Pittsburgh, Estados Unidos, recuperado de http://d-scholarship. pitt.edu 
Amaya Amador, Ramón

I962 Destacamento rojo, México D.F., Ediciones Palomar.

Amaya Amador, Ramón

I990 Prisión verde, 6a edición, Tegucigalpa, Editorial Universitaria.

Amaya Fúnez, Carlos

2020 "Página oficial de Ramón Amaya Amador", https://www.ramon-amaya-amador.com (consulta: Io/10/2019).

Amaya Fúnez, Carlos

2020 "Destacamento rojo, Prólogo, 4a edición", https://www.ramon-amaya-amador.com/index.php/obras/prologos/Ioo-destacamento-rojo-prologo-4-edicion (consulta: 22/oI/2020).

Bajtín, Mijaíl M.

1998 Estética de la creación verbal, 8a ed., México, Siglo xxi Editores.

Becerra, Longino

I962 Prólogo de Destacamento rojo, México D.F., Ediciones Palomar.

Becerra, Longino

1990 Prólogo de Prisión verde, 6a edi., Tegucigalpa, Editorial Universitaria. Beverley, John

I987 "Anatomía del testimonio", Revista de Crítica Literaria Latinoamericana, 25, pp. 7-16, https://www.jstor.org/stable/4530303

Diccionario de la literatura centroamericana 2007 (coord.) Albino Chacón, San José, Editorial Costa Rica.

Gaínza, Gastón

I994 "La lectura de la otredad", Letras, 29-30, pp. 9-20, recuperado de http:// www.revistas.una.ac.cr

Grinberg Pla, Valeria y Werner Mackenbach

2006 "Banana novel revis (it) ed: etnia, género y espacio en la novela bananera centroamericana. El caso de Mamita Yunai", Iberoamericana (200I), 23, pp. I6I-I76, https://www.jstor.org/stable/41676099

Grinberg Pla, Valeria y Werner Mackenbach

2009 "Representación política y estética en crisis: el proyecto de la nación mestiza en la narrativa bananera y canalera centroamericana", en Valeria Grinberg Pla y Ricardo Roque-Baldovinos (eds.), Tensiones de la modernidad: Del modernismo al realismo, t. II. Hacia una historia de las Literaturas Centroamericanas, Guatemala, F\&G Editores. 
Mackenbach, Werner

2006 "Banana novel revisited: Mamita Yunai o los límites de la construcción de la nación desde abajo", Káñina, 2, pp. 129-138, recuperado de http:// www.repositorio.ciicla.ucr.ac.cr:808, ISSN: 0378-0473

Pérez Brignoli, Héctor

2018 Historia global de América Latina. Del siglo XXI a la Independencia, Madrid, Alianza Editorial.

Portillo Villeda, Suyapa Griselda

20II Campeñas, campeños y compañeros: life and work in the banana fincas of the north coast of Honduras, 1944-1957, tesis de doctorado presentada en la Universidad de Cornell University, recuperado de http://ecommons. cornell.edu

Posas, Mario

2019 "Movimiento sociales en Honduras", en Ramón Romero R. (ed.), Antología del pensamiento hondureño contemporáneo, Argentina, Clacso, https://www.jstor.org/stable/j.ctvnpokc9.16

Real Academia Española 2020 Diccionario de la lengua española, en línea, https://dle.rae.es/

Sevilla López Josué Joel 2019 Comunicaciones personales, 22 de octubre.

Sevilla López Josué Joel

2020 "Prisión verde y Destacamento rojo de Ramón Amaya Amador: representación política, actores sociales y enclave bananero", Perspectivas Sociales (en prensa), pp. I-I9.

Soluri, John

2013 Culturas bananeras: Producción, consumo y transformaciones socioambientales, Bogotá, Siglo del Hombre Editores.

Sommer, Doris

1992 "Sin secretos", Revista de Crítica Literaria Latinoamericana, 36, pp. 137I55, https://www.jstor.org/stable/4530627

Uhrhan Irving, Evelyn

1997 "Jacinta Peralta by Ramón Amaya Amador", World Literature Today, 4, p. 759, https://www.jstor.org/stable/40153322

Umaña, Hellen 2003 La novela hondureña, Ciudad de Guatemala, Editores Letra Negra. Vargas Llosa, Mario 2019 Tiempos recios, México, Alfaguara. 


\section{Viales-Hurtado, Ronny}

2006 "Más allá del enclave en Centroamérica: aportes para una revisión conceptual a partir del caso de la región Caribe costarricense (I8701950)" Iberoamericana (2001-), 23, pp. 97-III, https://www.jstor.org/ stable/41676095

\section{Yudice, George}

2010 "The Central American Caribbean: Rethinking Regional and National Imaginaries", en Anja Bandau and Martha Zapata Galindo (eds.), El Caribe y sus diásporas: Cartografía de saberes y prácticas culturales, Madrid, Editorial Verbum, recuperado de https://www.pdfs.semanticscholar.org

IvanNia BARBoza LeITón

Profesora asociada e investigadora de la Escuela de Estudios Generales de la Universidad de Costa Rica. Es doctora en Estudios de la Sociedad y la Cultura por la Universidad de Costa Rica. Asimismo, posee un Máster en Estudios de Cultura Centroamericana (con énfasis en Literatura Centroamericana) por la Universidad Nacional. Ha participado en congresos especializados en Costa Rica y en el extranjero, cuenta con publicaciones en las áreas de interés como la literatura centroamericana, la memoria y los estudios culturales.

Citar como: Ivannia Barboza Leitón (202I), "Las luchas campeñas en dos novelas bananeras hondureñas", Iztapalapa. Revista de Ciencias Sociales y Humanidades, núm. 91, año 42, julio-diciembre de 202I, ISSN: 2007-9176; pp. I55-I8I. Disponible en <http://revistaiztapalapa.izt.uam.mx/index.php/ $\mathrm{izt} /$ issue/archive $>$. 